\title{
Ruthenium-Catalyzed Ionic Hydrogenation of Aziridinium Cations
}

Hairong Guan, Sahar A. Saddoughi, Anthony P. Shaw, and Jack R. Norton*

Columbia University, Department of Chemistry, New York, New York 10027

\section{Supporting Information}

Kinetics of Hydride Transfer from $\mathrm{CpRu}(\mathrm{dppm}) \mathrm{H}$ (2) to Aziridinium Cation (1c) 


\section{S-2}

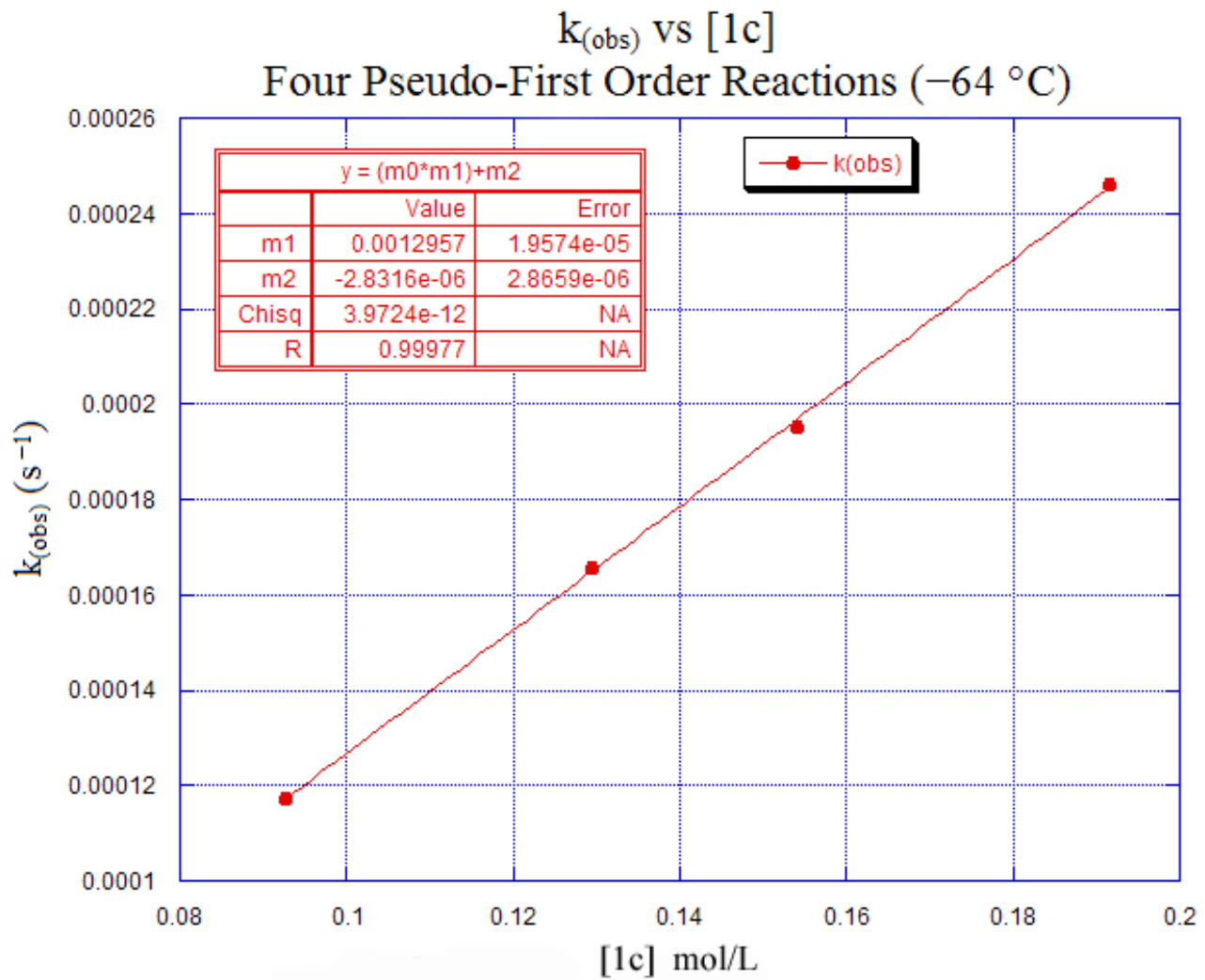

\begin{tabular}{|c|c|c|c|c|}
\hline $\mathrm{k}_{\text {(obs) }}\left(\mathrm{s}^{-1}\right)$ & Half-Life $(\mathrm{sec})$ & $\mu \mathrm{mol} \mathrm{1c}$ & {$[\mathbf{1 c}](\mathrm{mol} / \mathrm{L})$} & $\mathrm{RuH}(\mathrm{mol} / \mathrm{L})$ \\
\hline & & & & \\
\hline 0.00011742 & 5903 & 92.70 & 0.09270 & 0.0080 \\
\hline 0.00016570 & 4183 & 129.46 & 0.12946 & 0.0080 \\
\hline 0.00019502 & 3554 & 153.98 & 0.15398 & 0.0080 \\
\hline 0.00024607 & 2817 & 191.52 & 0.19152 & 0.0080 \\
\hline
\end{tabular}

Four pseudo-first order reactions, each in $1000 \mu \mathrm{L} \mathrm{CD}_{2} \mathrm{Cl}_{2}$ at $-64{ }^{\circ} \mathrm{C}$. 